\title{
MARIA DAS NEVES BATISTA PIMENTEL: A VOZ POR TRÁS DO VERSO
}

\author{
Elanir França de Carvalho* \\ Letícia Fernanda da Silva Oliveira**
}

\begin{abstract}
Resumo: Em seus folhetos de cordel, publicados na década de 1930, Maria das Neves Batista Pimentel reiterou os valores patriarcais vigentes na sociedade nordestina em que vivia, buscando exaltar, principalmente, a honra e a virtude como as maiores dádivas femininas. Em sua escrita, sob o pseudônimo do marido, Altino Alagoano, não buscou se aproximar do universo feminino, muito menos advogar em favor de uma maior participação feminina na sociedade. Neste artigo pretendemos investigar como a cordelista retratou as mulheres em seu folheto e também por que a autora reafirmou as regras sociais a que esteve submetida durante toda a vida, incorporando os dogmas e valores patriarcais às histórias que compunha em versos.
\end{abstract}

Palavras-chave: Maria das Neves Batista Pimentel. Literatura de Cordel. Mulher. Autoria feminina. Patriarcalismo.

Abstract: In her string literature, published in the 1930s, Maria das Neves Batista Pimentel reiterated patriarchal values prevailing in the Northeastern society in which she lived, seeking to exalt, mainly, the honor and virtue as the greatest female gifts. In her writing, under the pseudonym of her husband, Altino Alagoano, she did not seek to approach the female universe, let alone advocate for bigger female participation in society. In this article we intend to investigate how the poet portrayed the woman in her booklet and also why the author reaffirmed the social rules to which she was subjected throughout her life, incorporating the dogmas and patriarchal values in the stories composed by her in verse.

Keywords: Maria das Neves Batista Pimentel. String Literature. Woman. Female authors. Patriarchy.

\section{Introdução}

No Nordeste do início do século XX, adentrar o mundo dos cordéis, sendo uma mulher, não era uma tarefa fácil, pois tanto a cantoria como a literatura de folhetos não deixava brechas para a participação feminina cujo papel reservado, naquela sociedade fortemente marcada pelos dogmas católicos e valores patriarcais, era o de esposa e mãe. Portanto, a ausência de mulheres na produção de versos populares se deve também ao fato de que, uma vez destinadas aos afazeres domésticos e ao papel de mãe, restava-lhes apenas o silêncio e a reclusão. (QUEIROZ, 2006, p. 48).

No ensaio intitulado Um teto todo seu (2014), Virginia Woolf apresenta uma série de questionamentos acerca da escrita feminina. O mais importante deles talvez seja aquele que investiga o porquê de as mulheres serem sempre alvo da ficção escrita pelos homens, mas nunca autoras de suas próprias histórias. Sondando obras de séculos esparsos, Woolf (2014, p. 82) observa que poucas são as mulheres que se sobressaem a ponto de terem suas obras publicadas com obtenção de fama, e cita, como os maiores exemplos e exceções de sucesso, Jane Austen, as irmãs Charlotte e Emily Brönte, e George Eliot ${ }^{1}$, autoras de importantes

\footnotetext{
* Doutora em Letras pela Universidade de São Paulo-USP, docente da Universidade Federal do ParáUFPA/Campus Altamira. Endereço eletrônico: elanirfc@gmail.com

** Graduada em Letras pela Universidade Estadual Paulista "Júlio de Mesquita Filho", UNESP/Assis. Mestranda do Programa da Pós-Graduação em Letras da Faculdade de Ciências e Letras da UNESP/Assis. Endereço eletrônico: leticiafsoliveira@gmail.com

1 Mary Ann Evans optou pelo pseudônimo de George Eliot para que seu trabalho fosse levado a sério, pois mesmo em uma época em que as mulheres já haviam começado a publicar seus romances, a autora buscava se afastar do estereótipo de que as mulheres só escreviam romances leves.
} 
romances mundialmente conhecidos, entre estes Orgulho e preconceito (1813), Jane Eyre ${ }^{2}$, O morro dos ventos uivantes (1847) e Middlemarch: um estudo da vida provinciana (1847).

A escritora britânica chega à conclusão de que são poucas as mulheres que se destacam no mundo da escrita, porque a grande maioria mal sabia ler, pois eram educadas apenas para cumprirem seus afazeres domésticos e as trivialidades que as mantivessem dentro do lar e longe de sérios questionamentos. Para demonstrar a diferença que havia entre a trajetória de um homem e de uma mulher enquanto autores, Woolf (2014, 59-61) cria a história de uma hipotética irmã de William Shakespeare, como forma de deixar claro que o fato de ser mulher impossibilitou que muitas autoras pudessem, ou conseguissem realizar o feito de escrever suas histórias. Para a autora, a irmã de uma figura semelhante à do dramaturgo britânico viveria sempre à sombra dos seus feitos, impossibilitada de obter o mesmo sucesso e reconhecimento. Com este exemplo, Woolf buscou reforçar que as mulheres estiveram sempre em menoridade perante as figuras masculinas, por mais brilhantes que pudessem ser.

Sobre as mulheres romancistas, Woolf $(2014$, p. 84) afirma que, sendo a mulher sempre atarefada, como a própria Jane Austen, seus romances seriam sempre escritos aos poucos, entre uma tarefa cotidiana e outra, e, às vezes, escondendo essa atividade de seus familiares e sempre dos visitantes eventuais. A mulher que fosse descoberta enquanto escritora seria alvo de riso e julgamento alheio. A escritora chega também à conclusão de que as mulheres sempre escreviam romances, pois este gênero representava a literatura mais fácil de ser produzida no contexto do cotidiano feminino, e por não exigir tanta concentração, como ocorre à poesia.

Em seu raciocínio, Woolf (2014, p. 57) afirma que, mesmo não sendo reconhecidas como autoras, muitas vezes eram as mulheres as transmissoras das lendas folclóricas, contando-as para os seus filhos ou para outras mulheres com quem conviviam. Em sua dissertação de mestrado, intitulada Mulheres cordelistas: Percepções do universo feminino na Literatura de Cordel (2006), a pesquisadora Doralice Alves de Queiroz faz uma afirmação em consonância com a da escritora britânica.

Durante muito tempo, os sentimentos, as visões do mundo, as aspirações femininas foram recalcados na escrita, e, salvo algumas exceções, foi talvez na oralidade e no âmbito doméstico que a voz feminina pôde dar sua contribuição artística e poética. (QUEIROZ, 2006, p. 13).

Preliminarmente, estas observações deixam bem claro que não só no Nordeste brasileiro, mas em todas as sociedades patriarcais, as mulheres tiveram sempre que transpor barreiras, quase intransponíveis em seus contextos, para adentrar no universo da escrita, geralmente dominado pelos expoentes da arte de narrar. $\mathrm{O}$ fato é que elas não se deixaram intimidar, embora muitas tenham sido obrigadas a travestir a voz e o pensamento para galgar o primeiro degrau, como ocorreu a muitas mulheres repentistas e cordelistas no sertão nordestino entre o final do século XX e começo do XXI.

\section{De repente, mulheres no cordel e no repente}

Um dos raros casos em que mulheres atuam como cantadoras é lembrado por Leonardo Mota em Sertão Alegre (1968): trata-se da famosa cantadora negra Rita Medeiros, que preferia ser chamada de "Rita Medêra" ao invés de "Medêro". Ao que tudo indica, Rita

\footnotetext{
${ }^{2}$ Publicado em série nos anos de 1871-2, em 1874 foi publicado como um único volume.
} 
alcança fama nesse meio tipicamente masculino pelo fato de identificar-se com o universo dos homens e reproduzir temas e valores que vinham sendo cantados há séculos no sertão pelos expoentes masculinos da cantoria: "Era cantadora e alcoólatra. Pornográfica, requestavam-na para reuniões patuscas. Pena é que de Rita Medeiros a tradição oral só conserve a lembrança do viver boêmio e a toada musical de seu cantar". (MOTA, 1968, p. 244).

No sertão de final do século XIX e início do século XX os duelos verbais não previam a participação de mulheres. Nas raras apresentações em que estas se arriscavam a travar um combate verbal com cantadores masculinos, tinham que provar, na agilidade do ritmo e da resposta exigida pela provocação do rival, que estavam aptas a ocupar um lugar naquele universo dominado exclusivamente pelos expoentes masculinos do repente. Em Cantadores (1978), Leonardo Mota cita algumas estrofes da peleja entre Jerônimo do Junqueiro e a cantadora Zefinha Chabocão em que, claramente, a desafiante procura convencer a plateia de que está preparada para duelar verbalmente com um homem e assim, atender às exigências do público. Ao fazê-lo, pede que seu rival a trate com paridade, inclusive declarando ser capaz de realizar proezas reservadas apenas aos valentões, tentando, desse modo, igualar-se ao cantador:

- Mais porém eu, seu Jerome,
Não quero acomodação...
Lhe peço, até por bondade,
Que não tenha compaixão!
Há muito, tenho notiça
Que o sinhô é valentão,
É uma tirana-bóia,
Um besouro de ferrão,
Uma onça comedeira,
Um horroroso leão...
Eu hoje quero mostrá-lhe
Que mato sem precisão:
Deixo-lhe o corpo furado,
Só renda de papelão...
(apud MOTA, 1978, p. 17).

Mesmo nas pelejas fictícias a mulher repentista procura igualar-se ao homem em "valentia" verbal e perícia na arte de narrar em versos cantados, como ocorre no famoso embate, reproduzido em cordel, entre Severino Simeão e Ana Roxinha, em que a desafiante se apresenta nos seguintes termos:

Meu nome é Ana Roxinha

Sou filha de poetisa

Que pegou José Gustavo

Quase dava-lhe uma pisa

Não apanhou mas ficou

Sem a cota da camisa.

(apud ROIPHE, 2013, p. 76).

$\mathrm{Na}$ visão dos poetas populares e cantadores a mulher só podia desempenhar dois papeis específicos na sociedade, de acordo com sua conduta: Virgem Maria ou Madalena/Dalila. No folheto $O$ poder oculto da mulher bonita, de João Martins de Ataíde, a mulher figura como uma das maiores dádivas para o homem, apesar de predestinada ao sofrimento: 
Nasceu a mulher no mundo

Para o exemplo do bem

Na sua penosa vida

Nunca faz mal a ninguém

Se houver quem isto escureça

Talvez inda não conheça

$\mathrm{O}$ valor que a mulher tem.

(ATAÍDE, 1976, p. 3).

Mark Curran (2011, p. 83) observa que o poeta afirma ter sido a mulher enviada "ao mundo para servir somente ao homem, para levar uma vida de atribulações e sofrimentos, para nunca fazer o mal". E caso ela seja "bem simpática" e não seja "como Dalila", terá boa aceitação no meio em que vive, diz Ataíde:

Sendo mulher bem simpática

Se não for como Dalila

Aonde ela conversa

Todo mundo quer ouvi-la

Se acaso possível for

Ela precisa um favor

Vão três ou quatro servi-la.

(ATAÍDE, 1976, p. 6).

No folheto O bataclan moderno (1953), de João Martins de Ataíde, cuja autoria é atribuída a Leandro Gomes de Barros, o perfil da mulher que adere à moda é esboçado nos seguintes termos:

De primeiro uma donzela

Andava bem prevenida,

Se acaso ia um passeio

Se encontrava ela vestida

Hoje essa mesma donzela

A moda obrigou a ela,

Sair p'ra rua despida.

[...]

As senhoritas de agora

É certo o que o povo diz,

Não há vivente no mundo

Da sorte tão infeliz;

Vê-se uma mulher raspada

Não se sabe se é casada,

Se é donzela ou meretriz.

Traz a cabeça pelada

Bem raspadinho o cangote,

$O$ vestido que ela usa

Tem trez palmos de decote

Sendo de frente ou de banda

Vê-se bem quando ela anda

$\mathrm{O}$ seio dando pinote.

(ATAÍDE, 1953, p. 1-2).

Não raro a mulher também foi representada como um "peso", um fardo para o marido, sendo rotulada de astuta e interesseira, como no folheto satírico $O$ casamento do 
velho e um desastre na festa (1913), de Leandro Gomes de Barros, em que um velho de setenta anos, chamado Manoel Lopes dos Anjos, se enamora de uma adolescente, propondolhe casamento:

\author{
Manoel Lopes dos Anjos \\ Nunca tinha se casado \\ Dizia sempre a mulher \\ É um volume pesado \\ Deus me livre de mulher \\ De médico e advogado. \\ A mulher n'uma algibeira \\ Chama-se tiro seguro \\ Porque ela entra n'um bolso \\ Que só fogo no monturo \\ Só trinchete em melancia \\ Colher em mamão maduro. \\ (BARROS, 1913).
}

Embora as mulheres gozassem de representações nem sempre favoráveis na literatura de folhetos do começo do século XX, existem aqueles casos em que elas figuram como boas esposas, prendadas, religiosas e fiéis ao marido. Na maioria das vezes em que são mencionadas, protagonizam histórias exemplares - reelaboradas, sobretudo, a partir de narrativas medievais aportaram no Brasil passando a integrar a "biblioteca do sertão" -, que deviam servir de modelo de conduta para as mulheres do sertão. Dentre os mais reproduzidos e difundidos nas feiras e praças, destaca-se a História da Imperatriz Porcina (1944), de João Martins de Ataíde, um decalque da narrativa homônima do século XVI, cuja autoria é atribuída a Baltasar Dias, poeta cego da Ilha da Madeira. Na versão nordestina em cordel, Porcina, esposa de Ledônio, Imperador de Roma, era

$$
\begin{aligned}
& {[\ldots]} \\
& \text { Um primor de formosura, } \\
& \text { Era um anjo ideal } \\
& \text { Um modelo de candura } \\
& \text { Seu esposo mui vaidoso } \\
& \text { Sentia-se ele orgulhoso, } \\
& \text { Com tão linda criatura. } \\
& \text { A imperatriz Porcina } \\
& \text { Tinha fina educação, } \\
& \text { Filha de um rei da Hungria } \\
& \text { Império de outra nação } \\
& \text { Foi criada na riqueza } \\
& \text { Porém amava a pobreza } \\
& \text { De todo seu coração. } \\
& \text { (ATAÍDE, 1944, p. 1-2). }
\end{aligned}
$$

Nessa mesma direção segue o folheto História de D. Genevra (2007), do poeta e excomboieiro José Galdino da Silva Duda, o Zé Duda, escrito no final do século XIX, mas reeditado até hoje. A história de Genevra é uma adaptação da novela de "madonna Zinevra e Bernabò da Genova", do Decameron (1348) de Giovanni Boccaccio. Neste folheto o poeta popular louva os predicados de dona Genevra que, no decorrer da narrativa, será falsamente acusada de adultério, tendo que provar sua inocência para o marido. Na adaptação da 
narrativa italiana para o folheto o poeta acrescenta várias outras virtudes na descrição de Genevra que não se encontram no Decameron, mas que devem servir de modelo para o público leitor/ouvinte feminino. Segundo a versão nordestina, Genevra era uma mulher

[...] de grande habilidez

Lia, escrevia e contava

Falava bem português

Italiano e latim

Grego, alemão e francês.

Chamava Dona Genevra

Amava muito ao marido

Ele chamado Bernardo

De todos bem conhecido

Neste lugar não havia

Outro casal tão unido.

Dona Genevra sabia

Cortar, bordar e coser

Finalmente era modesta

Tudo sabia fazer

Em lugar de cozinheira

Não tinha mais o que aprender.

(DUDA, 2007, p. 1).

No folheto Os martírios de Genoveva (2006), outra narrativa oriunda da Europa medieval e cuja autoria é atribuída a Leandro Gomes de Barros, Genoveva, à semelhança de Santa Genoveva de Brabante - santa lendária cuja vida e martírio são narrados na Legenda aurea, de Jacopo da Varagine (1228-1298) -, é apresentada às mulheres nordestinas como um exemplo de renúncia que deve ser seguido com resignação:

Genoveva era dotada

De inteligência e engenho,

Nas feições dela se via

O mais perfeito desenho,

A natureza em orná-la,

Se esmerou e fez empenho.

[...]

Em tudo era preciosa,

Modesta e trabalhadora

Cortês e religiosa

Graças à educação

De sua mãe extremosa.

[...]

Ao travesseiro dos doentes

Era um anjo tutelar,

Divino consolador

Dos pobres desse lugar

Quem a visse estando triste

Tinha de se consolar.

(BARROS, 2006, p. 2).

Doralice Queiroz (2006) observa que foi somente a partir da década de 70 que as mulheres conquistaram definitivamente um espaço na literatura de cordel, não só 
reproduzindo histórias plenas de ensinamentos e moralidades, mas se posicionando diante das questões sociais e políticas do país, inclusive denunciado a real condição da mulher na sociedade, passando então a expressar o ponto de vista feminino sobre diversos assuntos antes relegados apenas à visão masculina da sociedade. Dentre estas mulheres cordelistas vale destacar os nomes das poetisas Maria de Lourdes Aragão Catunda (Dalinha Catunda), Maria Rosário Pinto e Josenir Lacerda, e inclusive citar a estrofe final do folheto A morena que calou o malandro, de Dalinha Catunda, que resume a atitude destas mulheres que no início do século XX, como Maria das Neves, precisavam escrever sob um pseudônimo e reiterar valores ainda marcadamente feudais:

\author{
A mulher hoje é esperta \\ Aprendeu a ser astuta \\ Sabe se posicionar \\ Adotou nova conduta \\ Dentro da sociedade \\ Vive nova realidade \\ Aguerrida é sua luta. \\ (CATUNDA, s. d., p. 8).
}

Em sua dissertação de mestrado Doralice Queiroz (2006) analisa a produção de duas importantes cordelistas: a da paraibana Maria Godelivie e a da cearense Salete Maria da Silva. Maria Godelivie, Poetisa e professora, buscou transmitir em seus versos novos valores relativos ao cotidiano e à modernização da sociedade, abordando temas como o adultério, a sexualidade e a integridade do caráter feminino (QUEIROZ, 2006, p. 80). Em seu folheto $O$ garanhão (2002), Godelivie retrata o adultério masculino da seguinte forma:

Minha nossa! Meu Senhor!

Onde fui eu me meter,

Arranjar duas mulheres?

Eu não tinha o que fazer?

Agora já não sei mais

Como o caso resolver

[...]

A carne é fraca, porém,

Adoro minha mulher

Que além d'outras coisas dá-me

Beijo, abraço e cafuné

Mas me deixei envolver

Pela linda Salomé.

Não que a minha mulher

Seja feia ou desdentada,

Ela é bastante bonita

Bem feita e bem conservada

Eu porém não resisti

A ter uma namorada.

(apud QUEIROZ, 2006, p. 68-69).

Diferente de como era retratada pelos poetas pioneiros, nestes versos a esposa figura como uma personagem que reúne boas qualidades. Embora a amante seja "linda", a esposa é também "bastante bonita", portanto as personagens não são retratadas de maneiras opostas. Se nos versos tipicamente masculinos o homem se gabava de suas infidelidades, aqui ganha traços de arrependimento, pois reconhece o verdadeiro valor de sua esposa, que por luxúria e 
desejo este traiu (QUEIROZ, 2006, p. 69). Salete Maria da Silva, advogada, ativista política e poetisa, cria seus versos se inspirando nas minorias sociais, utilizando como personagens as mulheres, os negros e os homossexuais. Busca retratar as mulheres pautando-se no papel feminino exercido na atualidade, na violência sofrida e também no assédio sexual e moral (QUEIROZ, 2006, p. 89). Incorpora, portanto, em suas criações, as vozes marginalizadas pela sociedade. Sua preocupação com esta temática fica explícita em seu folheto Embalando meninas em tempo de violência (2001):

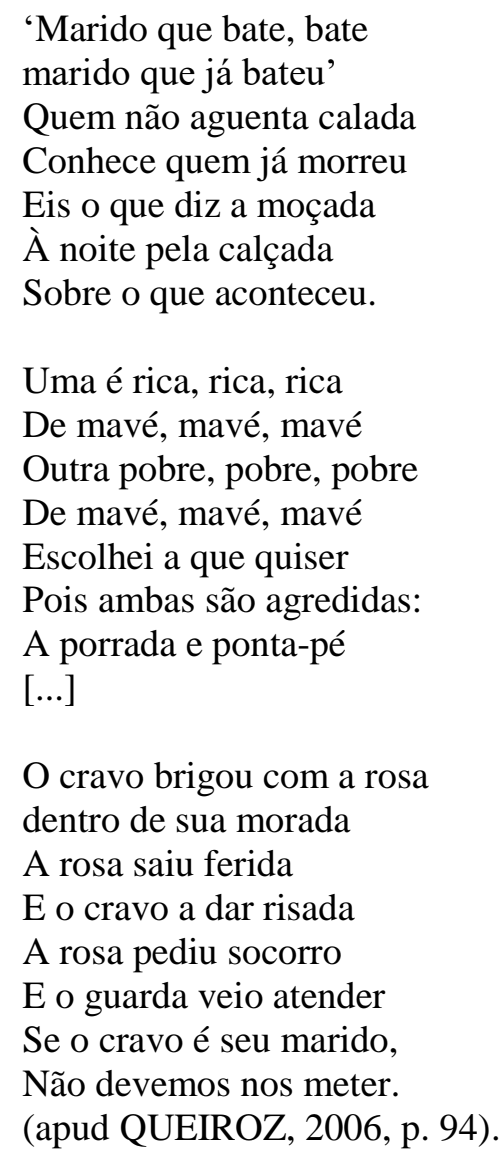

Utilizando cantigas populares como base para os versos que cria, neste folheto Salete pretende deixar claro que todas as mulheres estão sujeitas à violência doméstica, algo que independe de classe social. Sendo vítimas dos ataques masculinos, cabe às mulheres a revolta ou o silêncio, mas nenhuma destas opções lhes garante que serão de fato ajudadas pelas autoridades ou pelos conhecidos e familiares. Desta forma, Salete Maria da Silva dá voz a inúmeras mulheres que não podem expor a realidade que vivem dentro de seu lar, sendo diariamente vítimas de agressões, estupros e assassinatos por parte de seus maridos misóginos. E como se comportaram as poetisas que, no início do século XX, começaram a escrever seus folhetos, época em que este universo era tradicionalmente dominado pelos poetas de cordel e pelos repentistas?

\section{0 pioneirismo de Maria das Neves}

Em um cenário pouco favorável à representação de mulheres que não se ajustavam às normas patriarcais vigentes, em que a figura feminina devia se ater naturalmente à condição de beata, mãe e esposa, sendo-lhe vedado o direito de frequentar a praça ou a barbearia, lugares reservados aos homens, surge Maria das Neves Batista Pimentel, filha do famoso 
poeta Francisco das Chagas Batista. A poetisa, contrariando praticamente todas as normas vigentes, escreveu e publicou seu primeiro folheto de cordel em 1935. No entanto, como ela mesma confessa em entrevista concedida a Maristela Mendonça (1993), não foi fácil colocar seus escritos na praça, lugar que vinha sendo histórica e secularmente frequentado pelos expoentes masculinos da cantoria. Diante da dificuldade e movida pelo receio de não ter seus folhetos aceitos pelo público, Maria das Neves opta por usar o pseudônimo Altino Alagoano, nome do marido, como ela mesma declara a Maristela Mendonça:

Todos os folhetos que foram vendidos na Livraria de meu pai ou que foram impressos, tinham nome de homem, eram homens que faziam, não existia naquele tempo, folheto feito por mulher, e eu, para que não fosse a única, né?, meu nome aparecesse no folheto, não fosse eu a única, então eu disse: - Eu não vou botar meu nome.

Aí meu marido disse:

- Coloque Altino Alagoano. (PIMENTEL apud MENDONÇA, 1993, p. 70).

Como referido acima, Maria das Neves sabia que o fato de ser mulher limitava seus horizontes e que, por este motivo, deveria ocultar a sua verdadeira identidade. A cordelista opta por ocultar a verdadeira autoria dos folhetos, acreditando que, travestindo-se na pessoa do marido, teria seus folhetos aceitos pelo público que consumia este tipo de literatura. Mas o fato é que Maria das Neves não só teve de se ocultar por trás de um pseudônimo masculino. Ela teria outro desafio muito maior além do receio de não ser aceita na comunidade de poetas. Os valores transmitidos por sua poesia não podiam transgredir o modelo que vinha sendo seguido desde a Idade Média na Europa: suas protagonistas deviam continuar ocupando o mesmo lugar ocupado na tradição por Porcina, Genevra e Genoveva; suas mulheres não podiam aparecer ostentando corpos dissidentes nem transmitindo opiniões por meio de vozes dissonantes. Elas deviam permanecer ocupando, com resignação, o território da aceitação e da renúncia.

Quando seu marido, Altino Alagoano, sugeriu que publicasse folhetos, pois passavam por dificuldades financeiras, Maria das Neves respondeu afirmando que "traduziria" para a literatura de folhetos narrativas oriundas da "literatura alta", termo que ela usa para se referir às suas leituras eruditas. Foram, então, transpostos para a literatura em versos três romances, que deram origem aos seguintes folhetos: O Corcunda de Notre Dame, publicado em 1935, inspirado no romance homônimo de Victor Hugo; O amor nunca morre, inspirado no romance Manon Lescaut, do Abade Prévost, e publicado em 1938; e $O$ violino do diabo ou o Valor da Honestidade, inspirado no romance $O$ violino do diabo, de Victor Pérez Escrich, também publicado em 1938.

O interesse de Maria das Neves, tanto pela literatura erudita como pela literatura de folhetos, talvez se deva ao fato de ela ser filha de um dos maiores cordelistas nordestinos, Francisco das Chagas Batista (1882-1930), o qual, além de poeta, tinha a sua própria tipografia de cordéis e também uma livraria em que eram comercializados cordéis e livros. Ruth Brito Lêmos Terra (1983) observa que Chagas Batista era um leitor assíduo de obras eruditas, principalmente de autores como Victor Hugo, Eça de Queiróz e José de Alencar. Podemos concluir, então, que essa figura paterna não serviu apenas de inspiração para a poetisa, mas que também a auxiliou na sua inserção no mundo literário.

A poetisa e seu pai eram continuadores de uma longa tradição familiar de poetas e cantadores. Os Nunes-Batista, herdeiros de uma família homônima, ligavam-se estreitamente à cultura de sua gente e às manifestações populares marcadas pela musicalidade e pela oralidade, sendo precedidos por glosadores, cantadores e poetas. $\mathrm{Na}$ entrevista concedida a Maristela Mendonça, Maria das Neves exalta o orgulho que sente de si mesma e de seus familiares: 
Eu sou filha de poeta

e neta de repentista

meu avô era Ugolino

e meu pai Chagas Batista

também faço poesia

o poeta é um artista!

(PIMENTEL apud MENDONÇA, 1993, p. 86).

Em seu processo de criação Maria das Neves pretendia tornar mais acessível semântica e linguisticamente um texto de origem erudita para um público de leitores/ouvintes semiletrados ou totalmente sem conhecimento das regras da língua formal, à maneira dos "tradutores" medievais que colocavam em "romance" (mettre en roman), narrativas oriundas da literatura erudita. Outra estratégia que se tornaria importante para a aceitação do público seria optar pela reiteração dos valores patriarcais vigentes na comunidade, dentre os quais a honra e a virtude femininas:

Você sabe que o romance é feito numa literatura alta. O povo não entende, mesmo lendo não entende, não compreende e nem vai perder tempo para ler o romance. Então eu transformei aquela literatura no linguajar do povo, no modo que o povo fala, que o povo entende. (...) eu peguei o miolo. A coisa mais, que me interessa. (...) $\mathrm{O}$ romance é o roteiro, agora aqui eu vou transferir toda essa história para o linguajar do povo e versar. (...) Eu não posso me afastar da linha do romance, não! Eu posso criar, ajudar no mesmo sentido. (...) Então aqui neste romance $O$ Violino do Diabo ou o Valor da Honestidade, então, a lição que eu salientei neste romance, foi a honestidade da moça e do velho, entendeu? Que aquele homem fez toda a trapalhada, toda a trapaça para iludir esta moça. (PIMENTEL apud MENDONÇA, 1993, p. 71).

Embora tenha escrito dois folhetos anteriores, nos deteremos no último cordel publicado pela poetisa na década de 30 e cuja primeira tiragem se esgotou rapidamente: $O$ Violino do Diabo ou o Valor da Honestidade (a primeira edição é de 1938). Neste folheto, Maria das Neves, ainda sob o pseudônimo de Altino Alagoano, conta a história de Maria, uma espécie de alter ego da autora. Maria é uma jovem musicista que opta pelo travestimento como um meio de frequentar as cantorias na companhia do pai, o velho Izidoro, algo impensável para uma mulher à sua época. Maria das Neves/Alagoano introduz a narrativa nos moldes da poesia tradicional, exaltando a honra e a virtude femininas:

A virtude é um lago

De águas bem cristalina,

Um espelho de diamante,

Uma joia rara e fina,

Onde o vício não pode

Lançar a mão assassina!

A mulher honesta e boa

De perfeita educação

É o cofre onde a virtude

Faz sua morada, então

$\mathrm{O}$ homem mais sedutor

Não mancha seu coração!

(ALAGOANO, 1981, p. 1). 
Tanto na ficção como na vida real, Maria, a personagem, e Maria das Neves, precisam ocultar suas verdadeiras identidades para exercerem a profissão de seus pais. Vestida como homem, à maneira de Diadorim, de Grande sertão: veredas, Maria desperta a atenção de Luiz, um jovem marquês que se impressiona com a sua beleza e resolve investigar mais detalhadamente aspectos de sua vida e personalidade. Logo acaba descobrindo que aquele personagem se trata de uma moça disfarçada, no entanto, o encanto por ela aumenta ainda mais, mas por estar desconfiado, devido ao fato de ter sido enganado por outra mulher, decide colocar à prova a honestidade da jovem. O episódio serve à autora do folheto de pretexto para colocar em cena personagens femininas que destoam da moral vigente no sertão e cujas condutas não devem ser imitadas, como haviam feito outros poetas ao introduzir em suas narrativas mulheres vivendo à margem do mortalmente aceito.

Em $O$ violino do diabo, de Maria das Neves, entram em cena personagens que estabelecem contrapontos à casta conduta de Maria, mormente pelo fato de protagonizarem ações não condizentes com os preceitos segundo os quais as mulheres deveriam ser fieis aos maridos, honestas e virtuosas. A primeira mulher que se destaca negativamente é uma das amantes de Luiz, a atriz Elizabeth, que o abandona para se casar com um velho rico, reforçando o estereótipo da mulher interesseira.

A amante respondeu:

- Luiz, peço-lhe perdão!

Encontrei um homem rico

Que pretende minha mão

E eu seria uma tola

Perdendo esta ocasião.

Pois eu convidei o velho

P'ra chá comigo tomar

Quero dar-te adeus Luiz

Embora fique a chorar!...

Pois eu só quero o dinheiro

Depois mando o velho andar!

Porém Luiz eu te amo

Nunca deixei de te amar

Eu só quero os milhões

E com o velho casar

Depois que pegar o peixe

Irei contigo falar

Perdoa caro marquês

A minha ingratidão

Mas preciso aparentar

Ter boa reputação

Apesar de ter-te dado

Alma, vida e coração!

(ALAGOANO, 1981, p. 19-20).

Esta personagem reúne características não condizentes com as de uma mulher honesta. Por ser uma atriz, Elizabeth alcançaria uma posição de destaque na sociedade em que vivia, e, além disso, tinha coragem de ir a público para trabalhar e era reconhecida por isso. Outra característica negativa era o fato de ser amante de Luiz e de ter renunciado à própria 
virgindade e à castidade, virtudes esperadas de uma mulher digna do casamento. $\mathrm{O}$ fato de se casar por ambição também demonstra como ela era ardilosa e maquiavélica.

Outra personagem explorada de maneira negativa pela cordelista é a viúva Rosália, que, por ser bastante engenhosa, ajuda o marquês a se aproximar de Maria e de seu pai.

Rosália era conhecida

Por viúva endinheirada

Frequentava a alta roda

De todos apreciada

E sempre em seu palácio

Havia festa afamada.

Rosália para iludir

Possuía habilidade

$\mathrm{Na}$ sua alma infame e negra

Reinava a perversidade

Ninguém como ela sabia

Fazer uma falsidade!

E Luiz já conhecia

O seu coração malvado

Porque em outra conquista

Ela o tinha ajudado

$E$ os planos que formava

Sempre dava resultado!

(ALAGOANO, 1981, p. 10).

Por ser viúva e muito rica, Rosália possuía uma vida social bastante ativa, permitindo que ela se relacionasse, pelos menos socialmente, com muitos homens. Embora se espere dela uma postura refinada, Rosália é falsa e perversa, e age inconsequentemente para atingir seus objetivos. Fica claro, no folheto, o repúdio dos falsos valores fomentados pelo dinheiro, tópica recorrente nos poemas de Leandro Gomes de Barros que, no folheto $O$ dinheiro (1909), constrói uma sátira cortante ao dinheiro, aos poderosos corruptos e às falsas aparências:

No dinheiro tem se visto

Nobreza desconhecida,

Meios que ganham questão

Ainda estando perdida,

Honra por meio da infâmia,

Glória mal adquirida.

$[\ldots]$

Porque o dinheiro na terra

É capa que tudo encobre,

Cubra um cachorro com ouro

Que ele tem que ficar nobre,

É superior ao dono

Se acaso o dono for pobre.

(BARROS, 1909, p. 1-4).

No folheto de Maria das Neves/Alagoano, Rosália, interesseira e mal intencionada, não nega ajuda a Luiz quando ele demonstra interesse em descobrir a verdade sobre a honestidade de Maria. Depois de, enfim, se aproximar da bela jovem, o marquês a coloca à prova de diversas maneiras, e sendo verdadeiramente uma mulher honrada e pura, Maria 
consegue provar o seu verdadeiro valor. Após várias tentativas Luiz então se convence e declara que ela é digna de seu amor, mas, principalmente, de seu respeito, e mostra que na verdade é um jovem rico que até então tinha se escondido por trás de um disfarce. No desfecho, semelhante ao das fábulas, o casal tem dois filhos, e na última estrofe acróstica, os dogmas e valores morais são reafirmados:
A virtude é invencível
Luiz a prova tirou
Tinha sua alma feliz
Inda mais feliz ficou
No nascimento dos filhos
O seu prazer aumentou.

(ALAGOANO, 1981, p. 47).

\section{Considerações finais}

Embora Maria das Neves tenha reafirmado os valores vigentes na sociedade em que vivia, permanece o fato de que, naquele momento e naquele contexto, não havia como seus versos se contraporem aos dogmas instituídos, por duas razões: suas rimas não agradariam o público, e, portanto, não seriam vendáveis, e também porque, tendo sido a cordelista criada no âmbito de uma sociedade tão restritiva como a Nordestina do começo do século XX, era natural que reproduzisse os mesmos valores consagrados pela maioria. Talvez a decisão de inserir suas personagens femininas em contextos nada convencionais para a época tenha sido tomada com o intuito de descontruir, mesmo que gradativamente e sob um pseudônimo, mentalidades estanques com relação ao papel da mulher e a real condição feminina no sertão.

Mesmo agindo de acordo com o mundo à sua volta, permanece o fato de que Maria das Neves foi a primeira mulher a produzir e publicar folhetos de cordel, rompendo, desse modo, a hegemonia de décadas de poetas e cantadores masculinos, inclusive no âmbito familiar em que o pais e os irmãos encabeçavam os grandes nomes da poesia popular. Por ser herdeira de Francisco das Chagas Batista, considerado o "braço poético do Nordeste", foi também natural, de certa forma, que a cordelista acabasse se dedicando à poesia popular.

Somente décadas após os folhetos de Maria das Neves é que as mulheres se consolidam como autoras de folhetos de cordel, passando a abordar não somente os seus próprios anseios, mas também temas sociais e políticos, que antes cabiam apenas aos homens. Autoras como Maria Godelivie e Salete Maria da Silva dedicam-se a tratar, sob uma nova perspectiva, a vida feminina, procurando deixar para trás os estereótipos masculinos vigentes na primeira metade do século XX. Embora Maria das Neves não tenha conseguido revelar sua verdadeira identidade nas praças e feiras onde seus folhetos eram divulgados, por receio de não ser aceita como poetisa, pelo menos no contexto familiar, em que todos eram homens e autores, ela conseguiu se impor, revelando seu talento e ocupando um lugar na hierarquia dos Nunes-Batista.

\section{Referências}

ALAGOANO, Altino. O violino do diabo ou o valor da honestidade. S. 1.: MEC/Pronasec Rural - SEC/Pb - UFPB - Funape, 1981.

ATAÍDE, João Martins de. História da Imperatriz Porcina. Recife: s. i., 1944. 
O bataclan moderno. Juazeiro: Editor José Bernardo da Silva, 1953.

1976.

. O poder oculto da mulher bonita. Juazeiro: Prop. Filhas de José Bernardo da Silva,

BARROS, Leandro Gomes de. O casamento do velho e um desastre na festa. Recife: LGB, 1913.

O dinheiro (O testamento do cachorro). Recife: s. n., 1909.

Os martírios de Genoveva. Fortaleza, CE: Tupynanquim/ABC, 2006.

BEAUVOIR, Simone de. O segundo sexo. Rio de Janeiro: Nova Fronteira, 2009.

CATUNDA, Dalinha. A morena que calou o malandro. Juazeiro do Norte, CE: SESC, s. d.

CURRAN, Mark. Retrato do Brasil em cordel. Cotia, SP: Ateliê, 2011.

DUDA, José Galdino da Silva. História de D. Genevra. Rio de Janeiro: ABLC, 2007.

MENDONÇA, Maristela Barbosa de. Uma voz feminina no mundo do folheto. Brasília: Thesaurus, 1993.

MOTA, Leonardo. Cantadores. Poesia e linguagem do sertão cearense. 5. ed. Rio de Janeiro: Cátedra, 1978.

. Sertão alegre. Poesia e linguagem do sertão cearense. Rio de Janeiro: Ediouro, 1968.

PERROT, Michelle. As mulheres ou os silêncios da história. Bauru, SP: EDUSC, 2005.

QUEIROZ, Doralice Alves de. Mulheres cordelistas: percepções do universo feminino na literatura de cordel. Mestrado Literatura Brasileira, Faculdade de Letras da UFMG, Belo Horizonte, 2006.

ROIPHE, Alberto. Forrobodó no sertão: leitura verbovisual de folhetos de cordel. Rio de Janeiro: Lamparina/Faperj, 2013.

TERRA, Ruth Brito Lemos. Memória de Lutas: Literatura de Folhetos do Nordeste, 18931930. São Paulo: Global, 1983.

WOOLF, Virginia. Um teto todo seu. São Paulo: Alaúde/Selo Tordesilhas, 2014.

Recebido em: outubro de 2016.

Aprovado em: dezembro de 2016. 